\title{
A INFLUENNCIA DA SOCIEDADE HIPERMODERNA E A DURAÇÃO RAZOÁVEL DO PROCESSO: MOROSIDADE, UM PROBLEMA DE ESTRUTURAÇÃO
}

\author{
THE INFLUENCE OF THE HYPERMODERN SOCIETY AND THE \\ REASONABLE DURATION OF THE PROCESS: MOROSITY, A \\ STRUCTURING PROBLEM \\ Eudes Vitor Bezerra \\ Danielle Milani Cunha
}

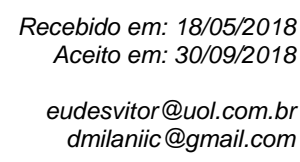
dmilaniic@gmail.com

\begin{abstract}
Resumo: A sociedade ultrapassou as barreiras do período pós moderno, caracterizada como hipermoderna, para a sociologia de Gilles Lipovestky. A rapidez é uma característica evidente e atinge 0 direito, posto que as pessoas almejam soluções rápidas. Neste cenário, a problemática existe na necessidade de identificar o que é Acesso à Justiça e duração razoável do processo que, não se restringem à tramitação célere e ao direito de ação. Portanto, analisar-se-á as contribuições possíveis para dirimir a morosidade judicial propiciando o acesso à ordem jurídica justa por meio de duração razoável e prestação da tutela jurisdicional a contento. Como hipótese inicial tem-se a imprescindível reestruturação do Poder Judiciário, isso porque, o aumento dos direitos fundamentais após a Constituição Federal de 1988 culminou na majoração da litigiosidade causando colapso do Poder Judiciário. Utilizar-se-á, para tanto, o método hipotético dedutivo.
\end{abstract}

Palavras-chave: Sociedade Hipermoderna. Duração Razoável do Processo. Acesso a Justiça. Estrutura do Judiciário.

\begin{abstract}
Society has overcome the barriers of the postmodern period, characterized as hypermodern, to the sociology of Gilles Lipovestky. Speed is an obvious feature and reaches the right, since people crave quick solutions. In this scenario, the problem exists in the need to identify what is Access to Justice and reasonable duration of the process, which are not restricted to the speedy procedure and the right of action. Therefore, the possible contributions to resolve delinquency by providing access to the fair legal order by means of a reasonable duration and the provision of judicial protection to the satisfaction will be analyzed. As an initial hypothesis is the essential restructuring of the Judiciary, because the increase of fundamental rights after the Federal Constitution of 1988 culminated in the increase of litigiousness causing a collapse of the Judiciary. The hypothetical deductive method will be used for this purpose.
\end{abstract}

Keywords: Hypermodern Society. Reasonable Duration of the Process. Access to Justice. Structure of the Judiciary.

\section{INTRODUÇÃO}

A evolução de novos paradigmas de tempo, relações interpessoais, cultura e satisfação da sociedade intensificaram-se no fim do século XX. As inovações tecnológicas proporcionaram à sociedade perspectiva hodierna modificando inclusive as necessidades básicas do ser humano atual.

Dessa forma, o termo modernidade não se enquadra mais como adequado, para Gilles Lipovetsky o termo foi superado e o que melhor caracteriza a sociedade é hipermoderna, como será explanado no primeiro capítulo. A sociedade hipermoderna é caracterizada pela rapidez, pela 
preocupação com a inovação, pela volatilidade das relações, consumo exarcebado e, em decorrência disso, as pessoas enquanto seres individuais e únicos são preteridas.

Diante deste panorama sociológico marcado pelo imediatismo e pela fluidez das relações, as pessoas que se socorrem do Poder Judiciário almejam rápida solução de seus conflitos.

No entanto, consiste um desafio determinar como o acesso à justiça se efetiva frente aos anseios sociais de duração razoável do processo e de análise do mérito de maneira que se efetive o direito material do jurisdicionado esculpido na sentença preservando a segurança jurídica.

O princípio fundamental da duração razoável do processo, previsto na norma Constitucional, determina que todo processo deve ser concluído em tempo aceitável, porém a definição do que seria aceitável ou razoável será averiguado no segundo capítulo, isso porque não há como dizer que duração razoável e rapidez são a mesma coisa, pois o caso concreto exige ser analisado com afinco e apenas estabelecer lapso temporal exato para o término da demanda não realiza o propósito da Constituição.

Ainda, deve existir a preocupação com a segurança jurídica, logo, um princípio não deve se sobrepor a outro, na ponderação destes para concretização do acesso à justiça não se deve privilegiar a celeridade em detrimento da segurança jurídica e do devido processo legal, em suma, da preservação dos direitos materializados na sentença.

O acesso à justiça, por sua vez, não deve se restringir ao acesso ao Judiciário, eis que a mera possibilidade de ajuizamento de ações não resguarda o direito dos indivíduos, faz-se necessário um conjunto de passos cadenciados e ordenados que é o processo e, para tanto, a estrutura do Poder Judiciário não deve se limitar a permitir o acesso ao processo, mas um processo gerido de modo a culminar na satisfação dos anseios sociais de análise comedida de suas demandas e de provimento jurisdicional hábil a se efetivar.

Destacar-se-á as principais causas da crise do Judiciário no capítulo 3 , dentre elas 0 advento da Constituição brasileira de 1988 que trouxe um rol extensivo de direitos incompatível com a estrutura deste Poder.

Como hipótese inicial será adotada a premissa de que é imperioso reestruturar o Judiciário tendo como objetivo otimização do serviço prestado sem se distanciar da análise acurada do mérito, por exemplo, com o magistrado desempenhando um papel de gestor do processo em colaboração com os serventuários e demais operadores do direito.

O estudo pautar-se-á no método de abordagem hipotético dedutivo com base em pesquisas bibliográficas e documental. Adotar-se-á como marco teórico a obra "Tempos Hipermodernos" de Gilles Lipovestky, para averiguar a influência da hipermodernidade na resolução dos conflitos sub judice.

\section{OS ASPECTOS DA SOCIEDADE HIPERMODERNA E A SUA INFLUÊNCIA NO DIREITO}

A evolução social se acelerou pós século XX por meio das inovações e mudanças de pensamento que a sociedade transcendeu, acarretando em uma nova perspectiva do ser humano em seu ambiente social e de suas relações.

Revista do Direito [ISSN 1982-9957]. Santa Cruz do Sul, v. 2, n. 55, p. 136-149, maio/ago. 2018. https://online.unisc.br/seer/index.php/direito/index 
Atualmente, a fase vivenciada é a das aparências e da superficialidade, auxiliado em grande proporção pelos meios de comunicação utilizados para a exposição da vida privada na esfera pública.

Já há algum tempo, a famosa "prova de existência" de Descartes, "Penso, logo existo", tem sido substituída e rejeitada por uma versão atualizada para nossa era de comunicação de massas: "Sou visto, logo existo". Quanto mais pessoas podem escolher me ver, mais convincente é a prova de que estou aqui" (BAUMAN, 2011, p. 28).

Neste contexto, assevera ainda Zigmunt Bauman que "(...) a esfera pública (...) se encontra hoje inundada e sobrecarregada, invadida pelos exércitos da privacidade" (BAUMAN, 2011, p. 41)

A rapidez nas relações também é característica marcante da época, além do excesso de consumismo desenfreado e a globalização ${ }^{1}$, em que todas as informações se disseminam com agilidade, ademais as relações foram fragilizadas, pois o que impera é a substituição, por exemplo, dos amores, das amizades, das coisas e do trabalho.

A globalização não deve ser vista como um mal, ela tão somente fornece os meios para interligar os países ainda que remotos, cumpre um papel de minimização das fronteiras de tempo e de espaço ${ }^{2}$, visto que possibilita aos seres humanos locomoção rápida de informação, mercadorias e de si próprios.

Ocorre que, essa mutação dificultou a aptidão das pessoas para solucionarem seus conflitos, especialmente por conta da ausência de interesse em perder tempo se dedicando a "consertar", pois a regra é descartar. Assim, procuram soluções imediatistas e prezam pela rapidez.

Gilles Lipovestky, em sua filosofia classifica o período em que vivemos como hipermoderno, que ultrapassa a modernidade ${ }^{3}$ e a pós-modernidade ${ }^{4}$. $\mathrm{O}$ autor João Feres Junior considera que Max Weber foi filósofo que apresentou a modernidade de maneira mais completa justificando que:

É na Ética Protestante que a teoria da modernidade de Weber se apresenta de maneira mais completa. O texto explica o domínio da racionalidade instrumental na sociedade moderna como um produto da secularização da ética protestante puritana de controle do corpo e domínio do mundo exterior. Aqui temos uma teoria da gênese histórica da modernidade, de ética de uma minoria religiosa a espírito de uma época. Mas é também na Ética Protestante que Weber mostra uma forte influência de Nietzsche, ao pintar o quadro cinzento do homem moderno dominado pela racionalidade instrumental e, portanto, incapaz de eleger valores substantivos que possam dar sentido à sua vida: a gaiola de ferro, na tradução equivocada de Talcott Parsons." (FERES JUNIOR, 2010)

\footnotetext{
${ }^{1}$ A globalização é a integração mundial na qual ocorre partilha informações, culturas e mercado entre países diversos.

2 “(...) sua subordinação à inventividade e à capacidade de técnica humana e, portanto, a colocação do tempo contra o espaço como ferramenta da conquista do espaço e da apropriação de terras não são um momento pior para começar uma avaliação que qualquer outro ponto de partida. A modernidade nasceu sob as estrelas da aceleração e da conquista de terras, e essas estrelas formam uma constelação que contém toda a informação sobre seu caráter, conduta e destino". BAUMAN, Zygmunt. Modernidade liquida. Tradução de Plínio Dentzien. Rio de Janeiro: Jorge Zahar, 2001, p. 131.

${ }^{3} \mathrm{O}$ período da modernidade ocorreu entre o Renascimento e o século XIX, na qual se inovou o conceito na qual o homem deu relevância a racionalidade em detrimento da influencia religiosa

${ }^{4} \mathrm{Na}$ Pós-modernidade o capitalismo ganha espaço na sociedade, ocorrendo após o século XX, seria uma extensão à modernidade na qual a globalização é uma das suas principais características e o multiculturalismo abre portas ao conhecimento extra-territorial.
} 
A tradição ${ }^{5}$ de modo de vida vivenciada durante muitos séculos se alterou e a preocupação com o novo é o que almeja o ser humano. Assim, elucida Lipovestky e Charles:

Na hipermordenidade, não há escolha, não há alternativa, senão evoluir, acelerar para não ser ultrapassado pela "evolução": o culto da modernização técnica prevaleceu sobre a glorificação dos fins e dos ideais. Quanto mais o futuro é previsível, mais ele precisa ser mutável, flexível, reativo, permanentemente pronto a mudar, supermoderno, mais moderno que os modernos dos tempos heróicos. (CHARLES, LIPOVESTKY, 2004, p.54)

Logo, a sociedade hipermoderna ultrapassa a simples evolução espontânea e necessita de inovações constantes, por conseguinte, essa necessidade de rapidez atinge tanto as relações de consumo e pessoais, quanto o Poder Judiciário.

Em que pese a facilidade de acesso à informação, inclusive no que tange aos direitos legislados, à distância de "um clique" proporcionar o conhecimento teórico - ainda que superficial - a mesma facilidade não se opera na realização destes.

Ocorre que, as pessoas buscam no Judiciário a mesma rapidez que experimentam em suas relações, porém sabe-se que o processo judicial é burocrático e dotado de formalidades intrínsecas, por vezes excessivas, por outras imprescindíveis. O direito em si decorre das necessidades sociais, não as anteveem, persegue seus anseios e se amolda lentamente à estes. Assim, o Poder Judiciário que visa concretizar o direito, não responde com a rapidez intentada aos conflitos que the são subordinados.

A prestação jurisdicional de pacificação social não se finda na rapidez, como veremos nos títulos a seguir a qualidade e segurança nas relações jurídicas são importantes e superam a rapidez desmedida.

\section{A DURAÇÃO RAZOÁVEL COMO PRINCIPIO FUNDAMENTAL. O QUE É RAZOVEL?}

A duração razoável do processo esteve implicitamente no ordenamento jurídico brasileiro desde promulgação da Constituição Federal de 1988, como o advento da emenda constitucional 45/2004, foi alterado o art. $5^{\circ}$ inciso LXXVIII ${ }^{6}$, da Carta Magna passando a figurar este princípio explicitamente. Nos ensinamentos de Humberto Theodoro Junior:

É de observar que a duração razoável não foi propriamente introduzida em nosso processo pela Emenda Constitucional no 45. Já havia um consenso de que sempre esteve implícita na garantia do devido processo legal (CF, art. 5ㅜ, LIV). Isto porque não se pode recusar à economia processual, em si mesma, a categoria de um dos princípios fundamentais do moderno processo civil, e, assim, a garantia de duração razoável do processo já seria uma garantia fundamental originariamente consagrada pela Constituição de 1988. Com efeito, por força do $\S 2^{\circ}$ de seu art. $5^{\circ}$, os direitos e garantias

\footnotetext{
5 Tradição é a transmissão de costumes, comportamentos, memórias, rumores, crenças, lendas, para pessoas de uma comunidade, sendo que os elementos transmitidos passam a fazer parte da cultura.

${ }^{6}$ LXXVIII a todos, no âmbito judicial e administrativo, são assegurados a razoável duração do processo e os meios que garantam a celeridade de sua tramitação.
} 
fundamentais não são apenas os expressos nos diversos incisos daquela declaração, mas incluem, também,"outros decorrentes do regime e dos princípios por ela adotados, ou dos tratados internacionais em que a República Federativa do Brasil seja parte".(THEODORO JUNIOR, 2008, p.9)

No que tange os tratados internacionais o Pacto de San José da Costa Rica, do qual o Brasil é signatário desde 1992, consta a duração razoável do processo como direito fundamental do homem, logo, não obstante, o Código de Processo Civil em vigor desde 2016 dispõe no art. 4 que "As partes têm o direito de obter em prazo razoável a solução integral do mérito, incluída a atividade satisfativa".

Nota-se a preocupação do legislador em constar o devido processo legal como princípio fundamental do processo, ligado notadamente ao acesso à justiça, tendo em vista a necessidade de se satisfazer às pretensões da sociedade em tempo razoável.

Ocorre que a situação de fato da justiça brasileira é que a morosidade predomina nos processos judiciais, os quais demoram anos para serem finalizados. Os dados do Relatório Justiça em Números de 2017 - ano base 2016, demonstram essa realidade.

O relatório aponta que o tempo médio de tramitação de processos de na fase de conhecimento nas varas estaduais por exemplo demoram dois anos e um mês para a baixa do processo, já na fase de execução o tempo médio é de cinco anos e nove meses.

De acordo com os dados fornecidos no relatório é possível constatar também que a fase de execução na qual se busca apenas cumprir um direito pré existente, liquido e certo a morosidade para a baixa é maior ainda, fato que apenas certifica a ausência de duração razoável.

Essa demora no andamento processual prejudica o próprio acesso à justiça tendo em vista que a demanda acaba por não satisfazer a pretensão, prejudicando assim a relação jurídica, ocasionando o perecimento do direito material discutido. Nas palavras de Monica Bonneti Couto e Samantha Ribeiro Meyer- Pflug:

É que já se podia afirmar, antes mesmo do advento da EC 45 , que a
razoável duração do processo é inerente à própria garantia de acesso à
justiça, na exata medida em que uma atividade
jurisdicional morosa e/ou ineficiente esvazia por completo o conteúdo do
direito ao acesso à justiça. Em outros termos: o acesso à justiça só é ampla
e eficazmente garantido com o asseguramento de uma justiça célere,
efetiva e justa. (COUTO, MEYER-PFLUG, 2014)

Outro fator a se considerar que decorre da lentidão judiciária é o descrédito que o cidadão tem no acesso à justiça, segundo o Relatório do Índice de Confiança no Judiciário de 2017 realizado pela Fundação Getúlio Vargas averiguou-se que apenas $24 \%$ dos entrevistados confiam no Poder Judiciário, sendo esse índice de confiança menor do que nas Forças Armadas (56\%), Igreja Católica (53\%), Imprensa escrita - jornais (35\%), Ministério Público (28\%), grandes empresas (29\%), emissoras de TV (30\%) e Polícia (26\%).

Um processo de duração razoável não é apenas uma preocupação da Justiça brasileira, muitos países buscam alcançar a razoabilidade da duração processual, na Itália, por exemplo, o 
processo costuma durar três anos, fato que causou a revolta da sociedade procurando a união européia para intervir em seu favor, conforme discorre Paulo Hoffman:

Assim, diante de uma Justiça italiana lenta e morosa, os cidadãos italianos, apoiados na Convenção Européia, passaram a socorrer-se da possibilidade de recurso à Corte Européia como forma de salvaguardar seus direitos e exigir a finalização dos processos judiciais em tempo justo ou indenização pelos prejuízos materiais e morais advindos da exagerada duração do processo.

Essa situação causou grave transtorno político à Itália como membro da Comunidade Européia, além de natural abalo em sua soberania, principalmente em razão da forte pressão exercida pelos demais países, uma vez que tantos foram os processos de cidadãos italianos perante a Corte Européia que se causou uma morosidade da própria Corte, a qual se viu às voltas com uma carga excessiva de processos em razão da exagerada duração do processo italiano, que não conseguia mais julgar seus próprios casos em tempo adequado. Diante desse quadro, a Itália viuse obrigada $a$, inicialmente, introduzir o justo processo em sua Constituição e, às pressas, aprovar uma lei que prevê a possibilidade de os cidadãos italianos requererem indenização perante as próprias Cortes italianas, porquanto a Convenção Européia somente admite recursos à Corte Européia quando esgotada a jurisdição no país-membro ou na hipótese de inexistência de lei que preveja a possibilidade de o jurisdicionado exigir determinado direito perante seu próprio país de origem. (HOFFMAN, 2005)

Assim, nota-se que a morosidade não esta presente apenas no Judiciário pátrio, outros países sofrem com a demora processual tanto quanto os brasileiros, e preocupam-se em criar dispositivos que auxiliem no alcance de seus objetivos em tempo aceitável.

Quando a Carta Magna implementa a duração razoável como direito fundamental não determinou prazo específico para o que é razoável. Obviamente não há como determinar tempo de processo generalizando todas lides, pois depende do caso concreto, cada processo possui particularidades, desta forma, não somente o fator tempo que determina a razoabilidade.

O risco que se pode observar também é a confusão na hermenêutica ${ }^{7}$ da palavra duração razoável, não se pode confundir duração razoável com aceleração processual, não é possível dizer que um processo rápido tem duração razoável, até porque interferiria em todos os princípios constitucionais processuais, como o próprio acesso à justiça.

O excessivo número de processos em tramite, por si só, não justifica a morosidade, têm-se aliado a este o mau funcionamento e ausência de estrutura do Judiciário, o desrespeito aos prazos processuais por parte dos magistrados, dentre outros fatores.

A segurança jurídica é tão importante quando o tempo do processo, portanto, para ser considerado razoável deve considerar o respeito ao procedimento sem extrapolar os prazos já determinados, a possibilidade da determinação de audiência que não demore meses, por exemplo, e não deve haver impunidade para o Estado quando extrapolar os prazos cerceando o direito da parte à razoabilidade da duração.

\footnotetext{
${ }^{7}$ A palavra hermenêutica na antiguidade possuía relação com a interpretação da bíblia ou seja, a própria interpretação das palavras de Deus, tem origem grega e é significa interpretação.
} 
Conclui-se, portanto, que a falsa premissa de que a duração razoável esta ligada ao tempo, pode ser gravemente prejudicial, pois a necessidade de preservar a segurança jurídica é indispensável.

A pressão da legislação, da sociedade e das partes, em se alcançar a rapidez, podem acarretar em sentenças instantâneas nas quais a análise adequada do conflito não é relevante, juízes que engessam suas decisões sem avaliar devidamente o caso não são eficientes e eficazes. Nas palavras de Monica Bonetti Couto e Samantha Ribeiro Meyer- Pflug:

Preocupa-nos, porém, a leitura que se tem dado sobre a chamada e tão reclamada "eficiência do Poder Judiciário", calcada, precípua e notadamente, em critérios quantitativos que têm em mira a rapidez na prolação de sentenças. Nesse ambiente, parece deveras importante indagar e ponderar se essa eficiência ou rapidez pode ser obtida "a qualquer preço", ou "a qualquer título", na medida em que um indicador de quantidade nem sempre é sinônimo de qualidade. (COUTO, MEYERPFLUG, 2014)

Logo, nota-se que a justiça não deve ser feita a "qualquer preço", pois os princípios do acesso à justiça, devido processo legal e segurança jurídica não podem ser descartados. Visto consistirem um conjunto de direito dos jurisdicionados.

Dessa forma, faz-se necessário restabelecer a confiança da população no Poder Judiciário viabilizando não só a propositura da demanda, mas também a prestação razoável e eficaz da tutela almejada, proporcionando assim o devido acesso à justiça, que será debatido a seguir.

\section{AS CAUSAS DA MOROSIDADE JUDICIAL E O ACESSO À JUSTIÇA}

$\mathrm{O}$ acesso a justiça esta elencado nos rol de direitos fundamentais do ordenamento jurídico brasileiro, disposto na Constituição Federal de 1988, no art. $5^{\circ}$ inciso XXXV, que dispõe "XXXV "[..].a lei não excluirá da apreciação do Poder Judiciário lesão ou ameaça a direito, dando tutela a população de ter seu direito protegido pelo judiciário[...]".

O amplo rol de direitos fundamentais promovidos pela Constituição Federal, traz consigo a deferência à salvaguarda destes direitos através do acesso à justiça, princípio pelo qual se almeja que as pretensões dos jurisdicionados será obtida pela efetivação do que esta legislado, assim como corrobora Boaventura de Sousa Santos:

(...) Por um lado, a consagração constitucional de novos direitos econômicos e sociais e sua expansão paralela à do Estado de bem estar transformou o direito ao acesso efectivo à justiça num direito charneira, um direito cuja denegação acarretaria a de todos os demais. Uma vez destituídos de mecanismos que fizessem impor o seu respeito, os novos direitos sociais e econômicos passariam a meras declarações políticas, de conteúdo e função mistificadores (SANTOS, 1986)

Ocorre que, o acesso à justiça não se limita ao acesso ao judiciário, a simples permissão de propositura de ação não possui é o objetivo de tal principio, pois o que se busca é a verdadeira aplicabilidade do que é positivado. 
Na concepção de Kazuo Watanabe,

O princípio de acesso à justiça, inscrito no n. XXXV do art. 5을 da Constituição Federal, não assegura apenas acesso formal aos órgãos judiciários, e sim um acesso qualificado que propicie aos indivíduos o acesso à ordem jurídica justa, no sentido de que cabe a todos que tenham qualquer problema jurídico, não necessariamente um conflito de interesses, uma atenção por parte do Poder Público, em especial do Poder Judiciário. Assim, cabe ao Judiciário não somente organizar os serviços que são prestados por meio de processos judiciais, como também aqueles que socorram os cidadãos de modo mais abrangente, de solução por vezes de simples problemas jurídicos, como a obtenção de documentos essenciais para o exercício da cidadania, e até mesmo de simples palavras de orientação jurídica. (WATANABE, 2011)

Existe também a mitificação que promover justiça gratuita e assistência judiciária gratuita permite que a sociedade possa ter seus direitos tutelados, porém são fatores que apenas intensificam que é necessário desmitificar que para exercer acesso à justiça é a possibilidade de ajuizar ações, conforme aduz Monica Bonetti Couto e Laís Teixeira:

A preocupação relevada no início deste ensaio significa, então, dizer que, como se verifica, a cláusula do acesso à justiça significa, muito mais do que se permitir a entrada no Judiciário, permitir a saída do jurisdicionado, com a tutela jurisdicional adequadamente prestada, em tempo razoável. (TEIXEIRA, COUTO, 2013)

Assim, é possível constatar que acesso à justiça não é tão somente a oportunidade de se valer da tutela jurisdicional por meio de propositura de demandas, este princípio tem como objetivo intrínseco a salvaguarda de direitos e a solução de litígios independente do judiciário.

$\mathrm{O}$ acesso à justiça tem como escopo permitir a igualdade entre as pessoas independente de classe social, condição financeira ou cultural, ou qualquer fator que promova descrédito entre os cidadãos, aliás como visto anteriormente a desconfiança no poder judiciário por toda sociedade possui níveis descomunais.

Para Mauro Capelletti e Bryan Garth:

\begin{abstract}
Embora o acesso à justiça venha sendo crescentemente aceito como um direito social básico nas modernas sociedades, o conceito de "efetividade" é, por si só, algo vago. A efetividade perfeita, no contexto de um dado direito subjetivo, poderia ser expressa como a completa "igualdade de armas" - a garantia de que a condução final depende apenas de méritos jurídicos relativo das partes antagônicas, sem relação com as diferenças estranhas ao Direito e que, no entanto, afetam a afirmação e reinvindicação de direitos. Essa perfeita igualdade, naturalmente, é utópica. (CAPELLETTI, GARTH, 2002, p.6)
\end{abstract}

Naturalmente muitos fatores influencia nas dificuldades no acesso a justiça, ocorre que em meio essas dificuldades a atual conjuntura traz evidencia que o judiciário se mantem em crise numérica imensurável.

O Conselho Nacional de Justiça forneceu em 2011 o relatório dos 100 maiores litigantes, nota-se entre as entidades em destaque encontram-se principalmente o Estado e bancos, tais 
instituição detém alto poder aquisitivo, permitindo que não haja preocupação em evitar o litigio eis que procrastinar a resolução do conflito ou impedir este de surgir não Ihes afetam de maneira significativa principalmente no sentido financeira.

A crise numérica como já mencionado é apenas uma das causas que acarretam na crise judiciparia, porem não é o bastante para justificar a dificuldade do acesso a justiça e a morosidade processual.

O judiciário passa por um grave problema de estruturação que permite que processos perdurem mais tempo do que deveriam, sejam por desinteresse judicial, seja por ausência de boa vontade das partes ou até mesmo dos serventuários. O judiciário não obteve organização suficiente para tratar as demandas judiciais em tramite e futuras ao ingresso.

\section{A (DES) ESTRUTURAÇÃO DO JUDICIÁRIO}

O judiciário como entidade publica deve prezar pela assistência e preocupação pelos serviços prestados. A própria administração publica ${ }^{8}$ possui princípios que devem ser preservados de modo que forneça as pessoas qualidade devida, que exista a crença que seus direitos estão sendo preservados.

A Constituição Federal prevê no art. 5ำ princípios processuais $^{9}$, tais princípios não são devem ser considerados apenas como inerentes ao próprio processo e sim ao próprio sistema judiciário, visto que colocados em pratica trazem a segurança jurídica na qual os particulares precisam.

O que é evidente que com a ampliação de direitos que a Constituição Federal de 1988 proporcionou, o judiciário não tinha suporte e tampouco organização adequada para receber tais demandas, e não houve preocupação em estruturar o judiciário para que existisse eficiência na tramitação processual.

A extensão e a complexidade dos direitos sociais garantidos, bem como o grau de detalhamento combinados com a capacidade do Judiciário de exercer o controle da constitucionalidade das leis e atos normativos, propiciaram um aumento substancial das áreas de intervenção e atuação pública deste poder. (SADEK, 2004)

O acesso à justiça como visto nos capítulos anteriores é um principio fundamental inerente ao ser humano, ocorre que essa atravancada de direitos, conjuntamente com o direito de ação, acarretaram o aumento exponencial na demanda judiciária, permitindo a litigância de maneira desordenada.

A atual estrutura do Poder Judiciário não consegue ser eficaz, ou efetiva, com características marcas pela burocracia, morosidade e prestação de serviços de baixa qualidade, precários que não suprem a realidade social da sociedade e não consegue consagrar os princípios deveriam conduzi-la.

\footnotetext{
${ }^{8} \mathrm{O}$ art. 37 da Constituição Federal de 1988, prevê no caput os princípios da legalidade, impessoalidade, moralidade, publicidade e eficiência.

${ }^{9} \mathrm{O}$ art. $5^{\circ}$ da Constituição Federal de 1988, dispõe sobre os princípios processuais quais sejam isonomia, devido processo legal, contraditório e ampla defesa, celeridade, isonomia, duplo grau de jurisdição razoabilidade, duração razoável do processo, acesso à justiça entre outros.
} 
A crise não é apenas uma questão de números, não é apenas questão processual, normativa, ou a própria insegurança no sistema judiciário existe fenômenos que somatizados contribuem para a ineficiência da administração, como a ausência de fiscalização, concursos que proporcionam cargos vitalícios, sendo que não há preocupação com a qualidade do serviço prestado, não possuem a preocupação em exercer sua função com mais zelo e responsabilidade, e nesse quadro os operadores do direito também possuem sua parcela de responsabilidade eis que não estão preparados devidamente à lidar com essas situações, tendo em vista que não é observado o problema de estruturação como um todo.

Para Vladimir Passos de Freitas:

O Poder Judiciário, em todo o mundo, ainda que em intensidade e sob formas diversas, passa por uma situação complexa e contraditória. Por um lado, é criticado em razão da morosidade. Por outro, é procurado mais do que nunca para resolver as mais complexas controvérsias. Em uma sociedade que vem transformando costumes centenários, a última palavra é sempre do juiz, haja ou não lei a regular a matéria em discussão (FREITAS, 2007)

Ocorre que o excesso de burocracia necessário para manter a maquina estatal em funcionamento também acaba afastando a população e com o aumento das funções do estado a celeridade e eficiência está hoje em segundo plano. Nas palavras de Luiz Carlos Bresser Pereira: "Na verdade, a administração burocrática é lenta, cara, auto-referida, e pouco ou nada orientada para o atendimento das demandas dos cidadãos" 10

Para Boaventura Souza ${ }^{11}$ a democratização da administração da justiça é fundamental, a primeira sendo a constituição interna do processo, de maneira que haja maior envolvimento da população, menos burocratização, incentivo a conciliação, aumento de legitimidade e de poderes do juiz.

Assim, ocorre que o juiz não tem gestão da vara de atuação, possuindo um olhar minimalista dentro de suas funções. Para Sergio Pereira Braga e Samantha Ribeiro Meyer Pflug:

O conhecimento das técnicas de gestão poderá transformar o juiz que (apenas) julga em um juiz que (também) administra, e é este o modelo de magistrado que o Judiciário precisa: um juiz conhecedor de técnicas de gestão, que busque a eficiência em tudo que faz e que saiba se valer da utilização de indicadores e metas de desempenho no exercício de sua tarefa diária. (BRAGA, MEYER PFLUG. 2013)

Pode-se perceber que a te no aspecto de formação dos juízes e profissionais de direito não há especialização em administração e gestão que seria algo que auxiliaria para o trabalho no judiciário.

\footnotetext{
${ }^{10}$ BRESSER PEREIRA. Luiz. Da administração pública burocrática à gerencial. Revista Serviço do Serviço Público. Volume $120 . \quad$ Brasilia. 1996,. Disponivel em: https://revista.enap.gov.br/index.php/RSP/article/view/702/550.

${ }^{11}$ SANTOS, Boaventura de Sousa. Introdução à Sociologia da Administração da Justiça. Revista Crítica de Ciências Sociais, $n^{\circ}$ 21, Novembro de 1986, pp. 11
} 
O juiz por sua vez deveria, deveria atuar com gestor, preocupando-se com a produtividade e qualidade dos serviços prestados. Nas palavras de José Renato Nalini:

A prioridade no conhecimento jurídico em sentido estrito privou o juiz brasileiro de se dedicar à administração da unidade judicial, aos atributos de gerência e de gestão das atividades que são confiadas. O olhar exclusivo para o processo deixa o controle da atuação dos funcionários para a burocracia hoje em grande parte desalentada. Não se inova, não se cria e o discurso único é o pleito de mais servidores e equipamentos.(NALINI, 2011, p.135)

Logo, é evidente que existe uma responsabilidade do próprio juiz em prezar pelo bom funcionamento do judiciário.

A pergunta de difícil resposta sempre será qual a motivação que pode ser dada para que haja preocupação em desenvolver melhor o sistema judiciário, de maneira que se adapte as novas demandas e se crie um estrutura apta a funcionar de maneira eficiente.

A eficiência no judiciário não pode estar restrita a criação de leis, os direitos fundamentais de efetividade, eficácia, eficiência, celeridade, duração razoável do processo não devem ser apenas palavras escritas em vão.

A realidade é que não há órgãos fiscalizadores e motivadores para uma boa gestão judiciária.

Uma inovação valida seria a criação de órgãos que fiscalizem e penalizem de maneira real o descaso que ocorre judiciário, capacitar juízes, operadores do direito e serventuários a lidar com o sistema como uma verdadeira empresa, em busca de resultados satisfatórios para seus usuários.

\section{CONCLUSÃO}

A sociedade evolui ao ponto de se tornar hipermoderna, em muitos fatores a superficialidade e a necessidade de rapidez nas relações tende a prejudicar os conflitos que atingem o judiciário.

As pessoas acabam por procurar o judiciário de maneira paternalista, tendo em vista que evitam "perder tempo" em lidar com seus problemas, transferindo-os a um terceiro que possa soluciona-los, no caso o judiciário acaba fazendo esse papel. A sociedade hipermoderna não quer se desgastar com soluções quer apenas resolve-las de forma imediata. Nota-se também que existe uma permissibilidade para que o processo dure tempo desnecessariamente longo.

Por sua vez, o processo judicial tem como principio fundamental a duração razoável do processo, o qual não deve ser confundindo com sinônimo de rapidez, visto que, cada processo tem suas peculiaridades e a febre por apenas concluí-lo de imediato não proporciona a segurança jurídica necessária para sanar o conflito de maneira eficaz e efetiva, de maneira que não há credibilidade da população neste Poder.

O acesso à justiça em meio a esse conflito de morosidade restou prejudicado, tendo em vista o descrédito da população em crer na preservação de seus direitos por intermédio do judiciário, faz saber que, o acesso á justiça não se da única e exclusivamente a possibilidade de ajuizar ações, haja vista que tal direito é inerente a resguardo de direitos e não ao acesso a propositura de ação judicial.

Revista do Direito [ISSN 1982-9957]. Santa Cruz do Sul, v. 2, n. 55, p. 136-149, maio/ago. 2018. https://online.unisc.br/seer/index.php/direito/index 
É fato que o judiciário brasileiro ultrapassou a razoabilidade para a duração processual, como marco deste problema é possível identificar o advento da Constituição Federal de 1988, tendo em vista que o rol de direitos tutelados pelo estado se tornou exponencialmente maior que outrora, e quando estes direitos são infringidos e chegam ao Judiciário não há preparo e organização para receber tais demandas.

Logo, é possível constar que a ausência de estrutura para que haja harmonia entre direito material, processual e o próprio judiciário jamais foi uma preocupação relevante, a questão organizacional não foi elencada nas preocupações da legislação.

Assim, a situação atual é de total ausência de preocupação em otimizar serviços públicos, o cidadão se vê desamparado e descrente, pois não há qualidade no serviço, nem eficiência, tampouco se observa a preocupação e alterar este cenário pelos envolvidos.

Nota-se também que existe um grande déficit na própria formação de operadores do direito que não tem preparo adequado a lidar com a administração, função na qual seria viável haver experiência, visto que, qualquer profissional da área em determinado momento terá que lidar com a estrutura organizacional de seu meio de trabalho.

Cabe salientar a importância na preocupação em proporcionar a população um serviço de qualidade, com credibilidade, duração razoável e que preserve o acesso a justiça de maneira plena, assim como toda empresa se preocupa.

Assim, o presente artigo busca identificar como uma das formas de auxiliar na duração razoável do processo e na qualidade do serviço judiciário uma melhor estruturação dos próprios fóruns, varas e tribunais, nos quais o juiz seja mais ativo e atuar como um verdadeiro gestor, preocupando-se com todo funcionamento e não apenas com a forma instrumental de cada processo que the é confiado, sendo necessário incorporar métodos de gestão adaptados ao serviço público, resguardando assim os direitos fundamentais e processuais nos quais a lei positiva.

\section{REFERÊNCIAS}

BAUMAN. Zygmunt. 44 Cartas do Mundo Líquido Moderno. Rio de Janeiro: Jorge Zahar, 2011.

BAUMAN. Zygmunt. Modernidade liquida. Tradução de Plínio Dentzien. Rio de Janeiro: Jorge Zahar, 2001.

BRASIL. Código de Processo Civil. Disponível em: http://www.planalto.gov.br/ccivil_03/_ato20152018/2015/lei//13105.htm. Acesso em 03.11.2017.

BRASIL. CONSELHO NACIONAL DE JUSTIÇA. Justiça em Números. 2017. Disponível emhttp://www.cnj.jus.br/files/conteudo/arquivo/2017/11/100d387b0339d6d8544a29e30a3b2150.pdf. Acesso em 17.11.2017.

BRASIL. CONSELHO NACIONAL DE JUSTIÇA. Os 100 maiores Litigantes. 2011. Disponível em http://www.cnj.jus.br/images/pesquisas-judiciarias/pesquisa_100_maiores_litigantes.pdf. Acesso em 20.11.2017

BRASIL. Constituição Federal. Disponível em:

http://www.planalto.gov.br/ccivil_03/constituicao/constituicaocompilado.htm. Acesso em: 03.11.2017. 
BRESSER PEREIRA. Luiz. Da administração pública burocrática à gerencial. Revista Serviço do Serviço Público. Volume 120. Brasilia. 1996,. Disponivel em: https://revista.enap.gov.br/index.php/RSP/article/view/702/550. Acesso em 25.11.2017.

CAPPELLETTI, Mauro. GARTH, Bryant. Acesso à Justiça. Porto Alegre: Sergio Antonio Fabris Editor: 2002.

COUTO, Mônica Bonetti; MEYER-PFLUG, Samantha Ribeiro. Poder Judiciário, justiça e eficiência: caminhos e descaminhos rumo à justiça efetiva. Revista de Doutrina da 4ª Região, Porto Alegre, n.63, dez. 2014. Disponível em:

http://www.revistadoutrina.trf4.jus.br/artigos/edicao063/MonicaCouto_SamanthaMeyerPflug.html Acesso em 17.11.2017

FERES JUNIOR, João. Introdução a uma Crítica da Modernidade como Conceito Sociológico. Mediações - Revista de Ciencias Sociais. Paraná. 2010. Disponível em: http://www.uel.br/revistas/uel/index.php/mediacoes/article/view/8232/7183. Acesso em 10.11.2017.

FREITAS. Vladimir Passos de. A eficiência na Administração da Justiça. Revista AJUFERGS no 03. Rio Grande do Sul. 2007. Disponível em: arquivos-revista/3/aeficincianaadministraodajustia.pdf. Acesso em 17.11.2017

FUNDAÇÃO GETÚLIO VARGAS. Relatório ICJ Brasil. Disponível: https://bibliotecadigital.fgv.br/dspace/bitstream/handle/10438/19034/Relatorio-

ICJBrasil_1_sem_2017.pdf. Acesso em 14.11.2017.

GABARDO, Emerson. Eficiência e Legitimidade do Estado: uma análise das estruturas simbólicas do direito político. São Paulo: Manole, 2003.

HOFFMAN, Paulo. O direito à razoável duração do processo e a experiência italiana. In: Reforma do Judiciário: primeiros ensaios críticos sobre a EC 45/2004. Coord. Teresa Arruda Alvim Wambier [et al]. São Paulo: Editora Revista do Tribunais, 2005.

LIPOVETSKY, Gilles, CHARLES, Sebastian. Os Tempos Hipermodernos. Tradução Mario Vilela,São Paulo: Editora Barcarolla 2004.

MANCUSO, Rodolfo de Camargo. Acesso à justiça: condicionantes legítimas e ilegítimas. São Paulo: Editora Revista dos Tribunais, 2011.

MEYER-PFLUG, Samantha Ribeiro ; BRAGA, Sergio Pereira . A Administração da Justiça e a Morosidade no Poder Judiciário. Revista Jurídica da FEPODI, 2013. Disponivel em: http://www.publicadireito.com.br/artigos/?cod=75c6b2d6319e12f3 Acesso em 20.11.2017

NALINI, José Renato. Há esperança de Justiça Eficiente?. In: Vladmir Oliveira da Silveira; Orides Mezzaroba. (Org.). Justiça e o Paradigma da Eficiência. 1aed.São Paulo: Editora Revista dos Tribunais, 2011.

RIBEIRO, Paulo de Tarso Ramos. Direito e Processo: Razão Burocrática e Acesso a Justiça. São Paulo. Editora Max Limonad. 2002

SADEK. Maria Teresa. Judiciário: Mudanças e Reformas. Scielo. São Paulo. 2004. Disponivel em: http://www.scielo.br/scielo.php?pid=S0103-40142004000200005\&script=sci_arttext

SANTOS, Boaventura de Sousa. A administração e gestão da justiça: análise comparada das tendências de reforma. Observatório Permanente de Estudos da Justiça Portuguesa. Centro de Estudos Sociais. Faculdade de Economia da Universidade de Coimbra. Coimbra: nov.2001. Disponível em http://opj.ces.uc.pt/portugues/relatorios/relatorio_5.html Acesso em 20.11.2017. 
SANTOS, Boaventura de Sousa. Introdução à Sociologia da Administração da Justiça. Revista Crítica de Ciências Sociais, n²1, Novembro de 1986, pp. 11

TEIXEIRA, Laís S. R. S. ; COUTO, M. B. . O acesso à justiça e seu enquadramento como direito fundamental: contexto atual e evolução. In: TARTUCE, Fernanda; COUTO, Monica Bonetti; SILVA, Maria dos Remedios Fontes. (Org.). Acesso à justiça I. 1ed.Florianópolis: FUNJAB, 2013, v. , p. 24-43.

THEODORO JUNIOR. Humberto. Direito Fundamental à Duração Razoável do Processo. Revista Magister de Direito Civil e Processual Civil. Lex Magister. Porto Alegre. 2008

WATANABE, Kazuo. Acesso à Justiça e sociedade moderna. In: GRINOVER, Ada Pelegrini; DINAMARCO, Cândido Rangel; WATANABE, Kazuo (Orgs). Participação e Processo. São Paulo: RT, 1988

WATANABE, Kazuo. Política Pública do Poder Judiciário Nacional para tratamento adequado dos conflitos de interesses. Disponível em:

http://www.tjsp.jus.br/Download/Conciliacao/Nucleo/ParecerDesKazuoWatanabe.pdf. Acesso em 03 de nov. 2017

\section{COMO CITAR ESSE DOCUMENTO:}

BEZERRA, Eudes Vitor; CUNHA, Danielle Milani. A influência da sociedade hipermoderna e a duração razoável do processo: morosidade, um problema de estruturação. Revista do Direito, Santa Cruz do Sul, v. 2, n. 55, set. 2018. ISSN 1982-9957. Disponível em: <https://online.unisc.br/seer/index.php/direito/article/view/12113>. Acesso em: doi:https://doi.org/10.17058/rdunisc.v2i55.12113. 